\title{
Glutamine synthetase gene expression during the regeneration of the annelid Enchytraeus japonensis
}

\author{
Cintia Carla Niva $\cdot$ Jae Min Lee $\cdot$ Maroko Myohara
}

Received: 27 September 2007 / Accepted: 27 November 2007 / Published online: 9 January 2008

(C) The Author(s) 2008

\begin{abstract}
Enchytraeus japonensis is a highly regenerative oligochaete annelid that can regenerate a complete individual from a small body fragment in 4-5 days. In our previous study, we performed complementary deoxyribonucleic acid subtraction cloning to isolate genes that are upregulated during E. japonensis regeneration and identified glutamine synthetase $(g s)$ as one of the most abundantly expressed genes during this process. In the present study, we show that the full-length sequence of $E$. japonensis glutamine synthetase (EjGS), which is the first reported annelid glutamine synthetase, is highly similar to other known class II glutamine synthetases. EjGS shows a $61-71 \%$ overall amino acid sequence identity with its counterparts in various other animal species, including Drosophila and mouse. We performed detailed expression analysis by in situ hybridization and reveal that strong $g s$ expression occurs in the blastemal regions of regenerating E. japonensis soon after amputation. gs expression was detectable at the cell layer covering the wound and was found to persist in the epidermal cells during the formation and elongation of the blastema. Furthermore, in the elongated blastema, gs expression was detectable also in the presumptive regions of the brain, ventral nerve cord, and stomodeum. In the fully formed intact head, $g s$ expression was also evident in the prostomium, brain, the anterior end of the ventral nerve cord, the epithelium of
\end{abstract}

\footnotetext{
Communicated by D. A. Weisblat

C. C. Niva $\cdot$ J. M. Lee $\cdot$ M. Myohara $(\bowtie)$

Invertebrate Gene Function Research Unit,

National Institute of Agrobiological Sciences,

Tsukuba, Ibaraki 305-8634, Japan

e-mail: myohara@affrc.go.jp

C. C. Niva

e-mail: cintiacn@nias.affrc.go.jp
}

buccal and pharyngeal cavities, the pharyngeal pad, and in the esophageal appendages. In intact $E$. japonensis tails, gs expression was found in the growth zone in actively growing worms but not in full-grown individuals. In the nonblastemal regions of regenerating fragments and in intact worms, $g s$ expression was also detected in the nephridia, chloragocytes, gut epithelium, epidermis, spermatids, and oocytes. These results suggest that EjGS may play roles in regeneration, nerve function, cell proliferation, nitrogenous waste excretion, macromolecule synthesis, and gametogenesis.

Keywords Glutamine synthetase · Gene expression . Regeneration · Oligochaete annelid · Enchytraeus japonensis

\section{Introduction}

Some types of annelids exhibit remarkable regenerative abilities that are comparable to planarians. However, the regeneration mechanisms are thought to be quite different between planarians and annelids. Whereas planarians regenerate via totipotent stem cells (neoblasts) that are widely distributed throughout their bodies (Reddien and Alvarado 2004), annelid regeneration is thought to occur mainly through the dedifferentiation and subsequent redifferentiation of cells without any contribution from totipotent stem cells (Thouveny and Tassava 1998). In this respect, annelids regenerate in a manner similar to that of amphibians (Carlson 1998) but on a much larger scale. The elucidation of the annelid regeneration mechanisms is thus expected to provide valuable information that may allow us in the future to explore strategies to enhance the regenerative capabilities in vertebrates.

In our recent study, we have proposed the oligochaete annelid Enchytraeus japonensis as a new model system for 
regeneration studies (Myohara et al. 1999). E. japonensis has striking features that are highly advantageous in this regard: (1) It reproduces asexually by dividing its body into several fragments, which then regenerate a complete individual within 4-5 days, (2) artificially amputated fragments can also regenerate new individuals in the same manner, and (3) both asexual and sexual reproduction can be artificially induced in the laboratory (Myohara et al. 1999).

As an initial strategy toward the elucidation of the molecular mechanisms underlying annelid regeneration, we previously performed complementary deoxyribonucleic acid (cDNA) subtraction cloning using regenerating fragments of E. japonensis and intact animals (Myohara et al. 2006). Filter array screening subsequently revealed that about $38 \%$ of the forward-subtracted cDNA clones we isolated contained genes that were upregulated during regeneration. These clones hybridized with probes derived from regenerating fragments but not with probes from intact worms. Of these clones, 279 were then sequenced and found to contain 165 different sequences (79 known and 86 unknown). Among these 279 regeneration-upregulated clones, as many as $13(4.7 \%)$ were found to encode glutamine synthetase, a ubiquitous and key enzyme in nitrogen metabolism (Kumada et al. 1993).

Because of its abundance in our subtracted cDNA library, we cloned the full-length sequence of $E$. japonensis glutamine synthetase (EjGS). By reverse transcriptasepolymerase chain reaction (RT-PCR), we subsequently revealed that the expression levels of the glutamine synthetase gene $(g s)$ were consistently high during the regenerative process, with a gradual decline seen only in the very late stages, and our preliminary analysis by whole mount in situ hybridization further revealed strong $g s$ expression in the blastemal tissues of the regenerating fragments (Myohara et al. 2006). As these previous results suggested an important role for $g s$ in annelid regeneration, in the present study, we have examined the detailed expression pattern of $g s$ in regenerating fragments and intact worms and considered the possible roles of this enzyme in the biology of E. japonensis. This is the first detailed report of the sequence and expression of $g s$ in annelids.

\section{Materials and methods}

\section{Animals}

E. japonensis worms were reared at $24^{\circ} \mathrm{C}$ in $1.1 \%(\mathrm{w} / \mathrm{v})$ plain agar medium in disposable Petri dishes and were fed with rolled oats as previously described (Myohara 2004). Under these conditions, the worms grow continuously to about $10 \mathrm{~mm}$ long, consisting of 50-60 segments, and reproduces asexually by fragmentation every 2 weeks. To induce sexual reproduction, starved worms were cultured in wet leaf mold and refed with rolled oats as previously described (Myohara 2004).

Molecular analysis

The full-length cDNA of EjGS (accession number AB109095) has been isolated in our previous study (Myohara et al. 2006). Multiple alignments of the entire amino acid sequences of the glutamine synthetase proteins from representative species, which were obtained through GenBank/EMBL/DDBJ Data Bank and chosen to cover a wide range of phylogenic groups, were performed using ClustalW software (Thompson et al 1994). To avoid errors resulting from mixing of possible pseudogenes, only data originating from full-length messenger ribonucleic acid (mRNA) sequences were used.

In situ hybridization

Both sense and antisense digoxigenin (DIG)-labeled RNA probes were synthesized using the DIG RNA labeling kit (SP6/T7, Roche) as previously described (Myohara et al. 2006). Whole-mount in situ hybridizations were also performed as previously described (Myohara et al. 2006) with some modifications to enhance the signals. Briefly, hybridization was carried out overnight with $1 \mu \mathrm{g} / \mathrm{ml}$ of $g s$ DIG-labeled RNA probe at $55^{\circ} \mathrm{C}$. An anti-DIG alkaline phosphatase (AP) conjugate antibody (Roche) was preabsorbed by incubation for $2.5 \mathrm{~h}$ with fixed and rehydrated worms and used at a dilution of 1:2,000. In situ hybridization of paraffin sections $(6 \mu \mathrm{m})$ was carried out according to Hoshino et al. (1999) and Abe et al. (2003) with a few modifications. Briefly, sections were hybridized with DIG-labeled probes at a concentration of $100 \mathrm{ng} / \mathrm{ml}$ in probe diluent (Genostaff, Tokyo, Japan) at $60^{\circ} \mathrm{C}$ for $16 \mathrm{~h}$. Washes were then carried out using $5 \times$ Hybri-wash (Genostaff), and an anti-DIG AP conjugate antibody (Roche Applied Science, Tokyo, Japan) was then applied at a 1:1,000 dilution in Tris-buffered saline with $0.1 \%$ Tween 20 for $2 \mathrm{~h}$. After an overnight coloring reaction with nitro blue tetrazolium/5-bromo-4-chloro-3-indolyl-phosphate (Roche), the sections were counterstained with a Kernechtrot stain solution (Muto Pure Chemicals, Tokyo, Japan), dehydrated, and mounted in Malinol (Muto Pure Chemicals).

\section{Results and discussion}

Comparisons between E. japonensis glutamine synthetase and other known glutamine synthetases

A full-length 2,717-bp cDNA encoding gs was previously isolated from regenerating $E$. japonensis in our laboratory (Myohara et al. 2006). The sequence of this gene was found 
to contain a putative open reading frame of 360 amino acids with a calculated molecular mass of 40,509 Da. Because this was the first report in annelids of a full-length sequence for $g s$, we performed a database search in the present study to determine whether similarities existed with the $g s$ genes from other organisms. BLASTP analysis revealed that the deduced glutamine synthetase protein in E. japonensis (EjGS) was highly similar to known class II glutamine synthetases along its entire amino acid sequence (Fig. 1), which is well conserved across species (Kumada et al. 1993). Within the EjGS sequence, we identified a betagrasp (catalytic) and a noncatalytic domain, five conserved regions that are common to both prokaryotes and eukaryotes, ligands for $\mathrm{Mn}^{2+}$ ions, and an adenosine triphosphatebinding site (Pesole et al. 1991). An amino acid alignment between EjGS and the gs proteins from five invertebrates, sea anemone (Cnidaria), C. elegans (Nematoda), Pacific oyster (Mollusca), fruit fly (Arthropoda), sea urchin (Echinodermata), and four vertebrates (zebrafish, clawed frog, chicken, and mouse) showed that the overall amino acid identities between EjGS and its counterparts in various other animal species were within a range of $61-71 \%$ (Fig. 1).

Expression of the gs gene in the blastema of regenerating $E$. japonensis

By whole-mount in situ hybridization analysis, we detected strong gs expression in the blastemal region in regenerating fragments of E. japonensis (Fig. 2a). This expression was detectable from the early stages of the regenerative process in the cell layer covering the wound (Fig. 2b,k) and was found to persist in the epidermal cells during the formation and elongation of the blastema (Fig. 2c,d). There was also a notable concentration of this transcript in the region corresponding to the prostomium anlagen in the anterior blastema (Fig. 2e) and in the growth zone in the posterior blastema (Fig. 21). In situ hybridization analyses with paraffin-embedded sections additionally revealed that the gs expression pattern was mainly restricted to the epidermal cells in the early blastema (Fig. 2h) but did occur also in the inside tissues of the elongated blastema, where it was detected in the presumptive regions of the brain, ventral nerve cord, and buccal cavity (stomodeum), in addition to the prostomium and epidermal cells (Fig. 2i).

In the later stages of E. japonensis regeneration, by which time segmentation and organogenesis have almost completed, we observed that the gs expression levels in the blastemal regions had become reduced (Fig. $2 \mathrm{f}, \mathrm{m}$ ). In the fully formed intact head, however, the expression of this gene was detectable in the prostomium, brain, anterior end of the ventral nerve cord, epithelial cells lining the buccal and pharyngeal cavities, pharyngeal pad, and esophageal appendages (Fig. 2g,j; for E. japonensis morphology, see
Schmelz et al. 2000). In intact tails, gs expression was also evident in the growth zone in actively growing worms (Fig. 2n) but was absent in full-grown individuals in which the growth zone had become indistinguishable (Fig. 20). These observations are in agreement with the RT-PCR data included in our previous report, which showed that the expression levels of $g s$ were maintained at high levels during the early stages of regeneration, decreased temporarily in the later stages of this process, and were upregulated again in the fully formed intact worms (Myohara et al. 2006).

Expression of the gs gene in nonblastemal regions

In accordance with the abovementioned RT-PCR results, we found by in situ hybridization analysis in the present study that $g s$ expression was not restricted to the blastemal regions (Figs. 2a and 3a) but that less intense but clear expression could be observed also in the nephridia (Fig. 3a,b), chloragocytes (Figs. 2a, 3a-c), gut epithelium (Fig. 3c), epidermis of the nonblastemal regions of regenerating fragments (Fig. 3a), and also in intact worms (Fig. 3d,e). Nephridia are the excretory organs of oligochaete annelids and the chloragocytes (chloragogen cells) are specialized peritoneal cells of the intestine that participate in the metabolism, storage, and excretion of glycogen and lipids, thus resembling the vertebrate liver in terms of function (Jamieson 1981; Edwards and Bohlen 1996). The gs expression levels in these tissues were observed to be variable among the specimens examined and also among regions within the same specimen (Figs. 2a and 3c). We were unable to find any correlation between this pattern and a specific gut region or specific condition of our specimens, although an uneven distribution of glutamine synthetase has been reported previously in the mammalian and fish digestive tracts (James et al. 1998; Mommsen et al. 2003). Intense gs expression was also found in the spermatids in the seminal vesicles and in oocytes in the ovisacs in sexually mature worms (Fig. 3e).

General comparisons between the distribution of glutamine synthetase in different organisms

Glutamine synthetase is found in a wide range of organisms, including microorganisms, plants, and animals and is known to be expressed in a tissue-specific and developmentally controlled manner. In murine organs, glutamine synthetase activity is highest in the liver, followed in descending order by the epididymis, testes, uterine tube, stomach, kidney, brain, and adipose tissues (van Straaten et al. 2006). High glutamine synthetase expression in the brain, kidney, and liver has also been reported in fish (Murray et al. 2003). In Xenopus, gs transcripts have been detected in the ovary, kidney, eye, muscle, and embryo but 
E.japonensis sea anemone nematode

Pacific oyster fruit fly sea urchin zebrafish clawed frog chicken mouse

E.japonensis sea anemone nematode

Pacific oyster fruit fly sea urchin zebrafish clawed frog chicken mouse

E.japonensis sea anemone nematode Pacific oyster frui fly sea urchin zebrafish clawed frog chicken mouse

E.japonensis sea anemone nematode Pacific oyster fruit fly sea urchin zebrafish clawed frog chicken mouse

\section{E.japonensis} sea anemone nematode Pacific oyster fruit fly sea urchin zebrafish clawed frog chicken mouse

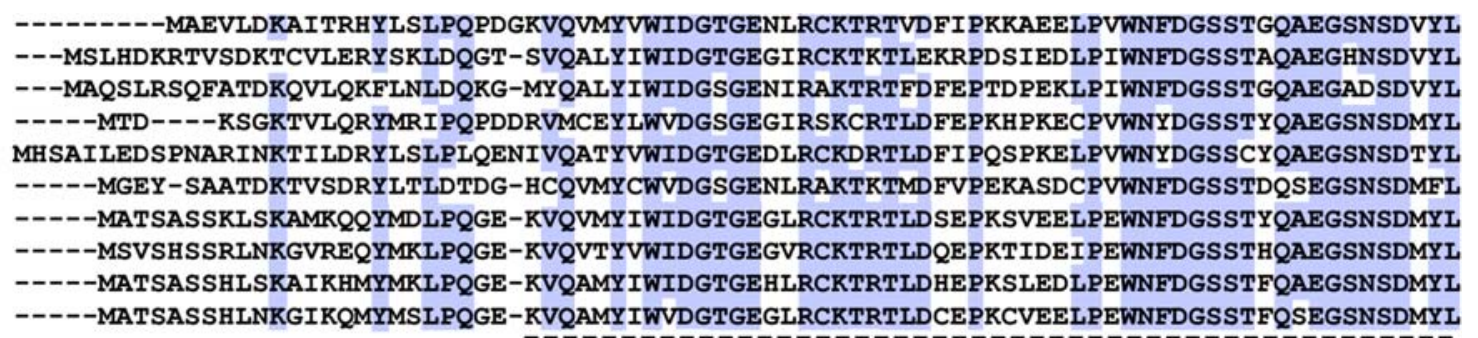
-

HPVALFNDPFRRGNNKIALCETYKYNNKPTETNHRKSCKEVME--RAQAEHPWFGIEQEYTLLDVDKHPYGWPKLGCPGPQGPYY HPVAIFKDPFRGGENILVLCETYTHDHKPTHTNNRKTCMNIMNDPEVKSSH PWFGIEQEYTLLDIDGHPLGWPKGGFPGPQGPYY KPVAIYPDPFRQGKNKLVMCETYDNKKKPTATNYRQRCKEVME--KAADQHPWFGMEQEYTLLDIDGHPFGWPKNGFPGPQGPYY HPVALY SDPFRMGKNKLVMCEVFKYNGKPAESNNRKSCNEVCE--KAAEEI PWFGIEQEYTMLDVDKHPLGWPKNGFPGPQGPYY YPVAIYKDPFRRGNNILVMCDTYKFDGTPTDTNKRKTCLEVAN--KCAAEEPWFGIEOEYTFLDFDGHPLGWPKNGFPGPOGPYY KPCALFRDPFRRGDNKLLMCEVYKYDWRPAETNYRKTCDEIMT--RAADTEPWFGIEQEYTLLGSDKWPFGWPKGGFPGPQGPYY FPQAMFRDPFRKD PNKLVLCDVLKYNHKPAETNLROSCKRIMD--MVQNOHPWFGMEOEYTLLGTDGHPFGWPSNGFPGPOGPYY IPVQMFRDPFCLDPNKLVMCEVLKYNRKSAETNLRHTCKKIME--MVNDHRPWFGMEQEYTLLGINGHPYGWPENGFPGPQGPYY RPAAMFRD PFRKDPNKLVLCEVFKYNROSADTNLRHTCRRIMD--MVSNOH PWFGMEOEYTLLGTDGHPFGWPSNCFPGPOGPYY HPVAMFRDPFRKDPNKLVLCEVFKYNRKPAETNLRHICKRIMD--MVSNQHPWFGMEQEYTLMGTDGHPFGWPSNGFPGPQGPYY -

CGVGADKVYGRDVLEAHYRACLYAGVKICGTNAEVMPAOWEFOVGPCEGIEIGDHLWMARFLLHRVAEDFGVVVTLDPKPMS-NW CGVGTNKVFGREVVEAHYRACLYAGVKIAGTNAEVMPAQWEYQVGPCEGIEMGDHLWISRYILHRVAEDFHVVVSFDPKPMPGDW CGVGANKVYGRDIVEAHYRACLYAGIQISGTNAEVMPGQWEFQVGPCEGIQMGDQLWVARYLLQRVAEEFGVIASFDCKPIKGDW CGVGANKVYGRDIVEAHYRACLYAGMKIAGCNAEVMPAQWEFQVGPCEGISVGDDLWVARYILHRVAEDFGVIVTFDPKPMPGDW CGVGANKVYARDIVDAHYRACLYAGIKVSGTNAEVMPAOWEFOVGPCEGISIGDDLWMARFLLHRISEEFGIVSTLDPKPMPGDW CGVGANKVYGRDIVESHYRACLYAGVKIAGSNAEVMPAQWEYQVGPCLGIEMGDHLWMSRFILHRVCEDFGVIATLDPKPMEGDW CGVGADKAYGRDVVEAHYRACLYAGVKICGTNAEVMPAOWEFOVGPCEGIEMGDHLWVARFLLHRVCEDFGVVASFDPKPIPGNW CGVGADKVYGRDVVESHYKACLYAGIKICGTNAEVMPSQWEFQVGPCEGIDMGDHLWMARFILHRVCEDFGVVATLDPKPMTGNW CGVGADKAYGRDIVEAHYRACLYAGVKIGGTNAEVMPAOWEFOVGPCEGIEMGDHLWIARFILHRVCEDFGVIVSFDPKPI PGNW CGVGADKAYGRDIVEAHYRACLYAGVKITGTNAEVMPAQWEFQIGPCEGIRMGDHLWIARFILHRVCEDFGVIATFDPKPIPGNW

NGAGAHTNYSTESMRQDGGIKAIEAAIEKLSLEHDRHIRMYDPRGGDDNRRRLVGSFETSSISEFSAGVANRGASIRIPRQVETD NGAGAHCNY STVGMREENGMRLIYEAIDKLEKNHDYHIKKYDPKQGQDNARRLTGRHETSSIYQFSHGVANRGASVRI PRQCAED NGAGCHTNFSTDKMRNPGGIDEIMSAINKLSLVHPQHIAYYDPHGGKDNERRLTGLHETASIDKFSYGVASRASSIRIPRSTDDD NGAGAHTNYSTVKMREDGGIKHIEDAIEKLSKCHDKHIKAYDPKEGEDNKRRLTGLHETSTINDFSAGVANRGASIRIPRQVAQD NGAGAHTNVSTKAMREDGGIRDIEKAVAKISKCHERHIRAYDPKOGQDNARRLTGKHETSSINDFSAGVANRGCSIRIPRGVNDD NGAGAHCNFSTLAMREDGGIDVMNEAIKRLGKRHKEHIRAYDPKNGEDNARRLTGRHETSSIDDFSSGVANRGASIRIPRQCGID NGAGCHTNF STKEMREEGGLKHIEESIEKLGKRHOYHIRAYDPKGGLDNARRLTGHHETSNINEFSAGVANRGASIRIPRSVGQE NGAGCHTNYSTESMRVEGGLKHIEDAIEKLGKRHDYHICVYDPRGGKDNSRRLTGQHETSSIHEFSAGVANRGASIRIPRQVGQE NGAGCHTNFSTKNMREDGGLKHIEEAIEKLSKRHQYHIRAYDPKGGLDNARRLTGFHETSSIHEFSAGVANRGASIRI PRNVGHE NGAGCHTNFSTKAMREENGLKCIEEAIDKLSKRHQYHIRAYDPKGGLDNARRLTGFHETSNINDFSAGVANRGASIRIPRTVGQE

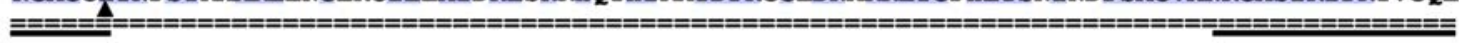

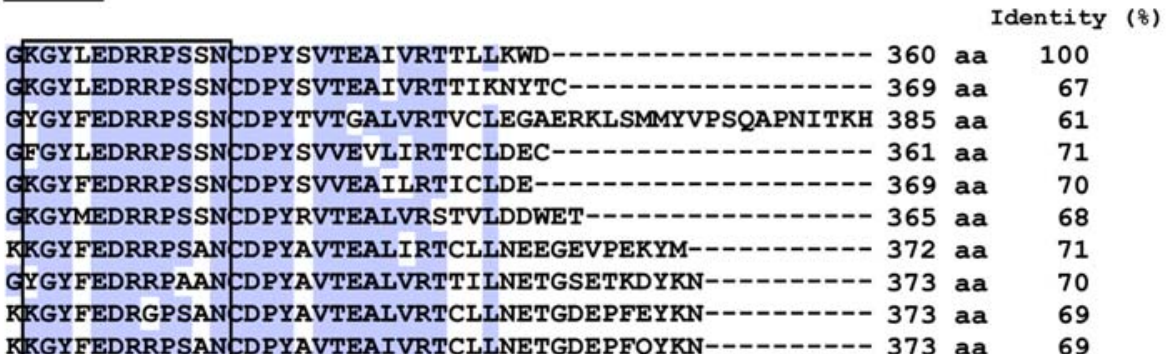

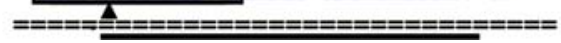

Fig. 1 Amino acid alignment of E. japonensis glutamine synthetase (EjGS) with representative GSs from various other species. The species and protein ID of the GSs listed here are as follows: Enchytraeus japonensis (BAE93509.1), sea anemone Aiptasia pallida (AAR36878.1), nematode Caenorhabditis elegans (NP_001041010.1), Pacific oyster Crassostea gigas (CAD90162.1), fruit fly Drosophila melanogaster (AAZ41780.1), sea urchin Paracentrotus lividus (AAC41562.1), zebrafish Danio rerio (AAH66735.1), clawed frog Xenopus laevis (AAH46681.1), chicken Gallus gallus (AAA48783.1), and mouse Mus musculus (AAH15086.1). Amino acid residues are indicated in blue when greater than or equal to $70 \%$ of these residues are identical in the ten representative species. The beta grasp domain, catalytic domain, and the regions that are conserved in prokaryotes and eukaryotes are underlined by broken single lines, broken double lines, and thick single lines, respectively. Ligands for $\mathrm{Mn}^{2+}$ ions are indicated by arrowheads. The ATP-binding sites are boxed. The protein length and overall amino acid identities with EjGS are indicated at the end of each sequence 


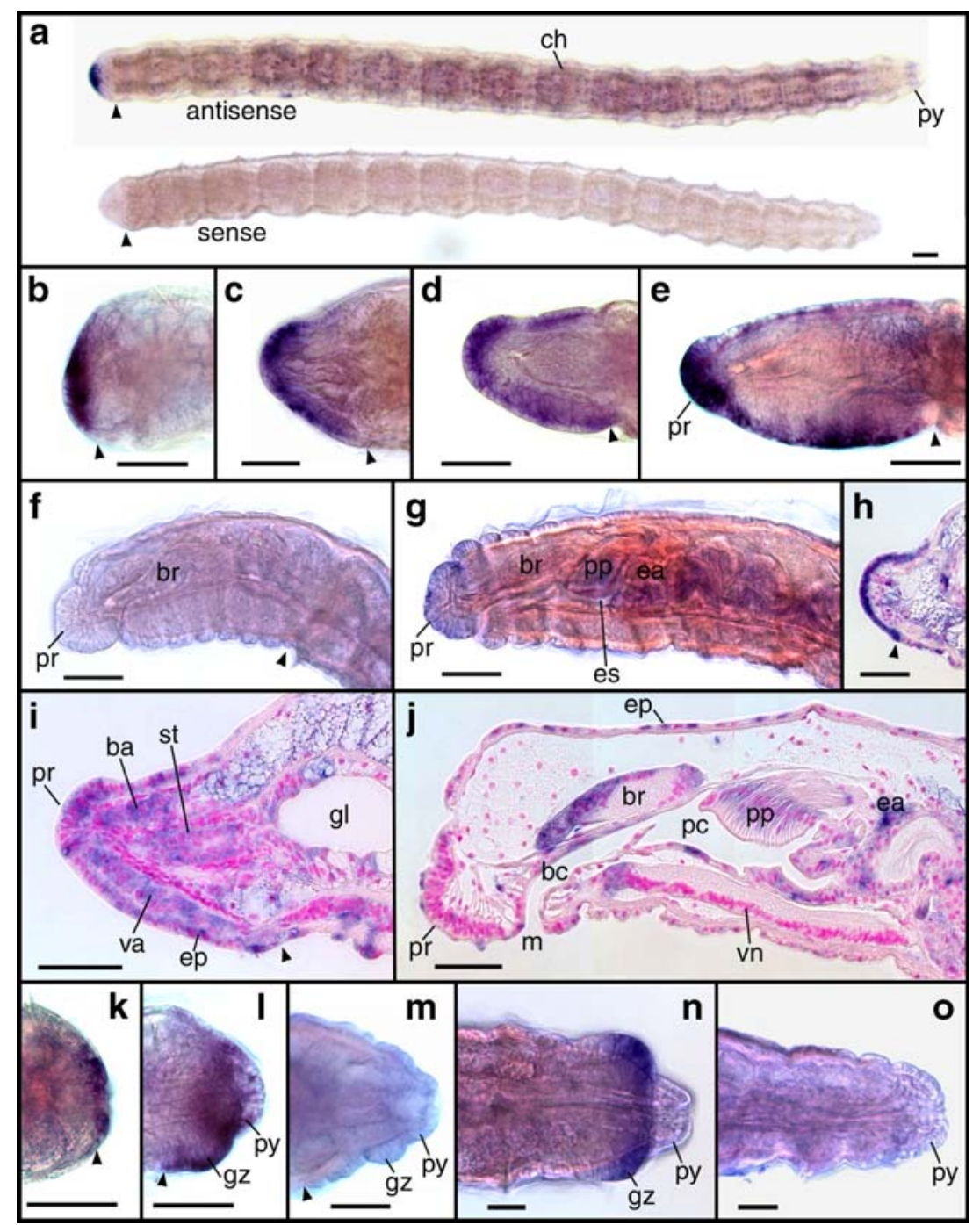

Fig. 2 Glutamine synthetase mRNA expression during regeneration in E. japonensis. Transcripts were detected using whole-mount in situ hybridization (a-g and $\mathbf{k}-\mathbf{o})$ or in situ hybridization analysis of paraffin-embedded sections (h-j) using an antisense gs riboprobe, with the exception of the lower specimen shown in a. The anterior is to the left, and the ventral side is down in each image. Arrowheads indicate the amputated sites. a Whole-body images of regenerating fragments at about 1 day after amputation with the anterior blastema and an intact tail. The lower specimen was hybridized with a sense probe. b-f Lateral views of anterior blastemas at about 1 (b), 1.5 (c), 2 (d), 2.5 (e), and 4 days (f) after amputation. $\mathbf{g}$ Lateral view of an intact head. $\mathbf{h}-\mathbf{i}$ Sagittal sections of anterior blastemas at about 1.5 (h) and 2 days (i) after amputation. $\mathbf{j}$ Sagittal section of an intact head. $\mathbf{k}-\mathbf{m}$ Lateral views of posterior blastemas at about $0.5(\mathbf{k}), 1$ (l), and 1.5 days (m) after amputation. $\mathbf{n}-\mathbf{0}$ Ventral views of intact tails in an actively growing (n) and a full-grown individual (o). $b a$ Brain anlage, $b r$ brain, $b c$ buccal cavity, $c h$ chloragocyte, $e a$ esophageal appendage, $e p$ epidermal cell, es esophagus, $g l$ gut lumen, $g z$ growth zone, $m$ mouth, $p c$ pharyngeal cavity, $p p$ pharyngeal pad, $p r$ prostomium, $p y$ pygidium, st stomodeum, $v a$ ventral nerve cord anlage, $v n$ ventral nerve cord. Scale bars, $50 \mu \mathrm{m}$ not in the brain, heart, liver, stomach, or testis (Hatada et al. 1995). In the case of invertebrates, little information is currently available regarding the expression profile of this enzyme and is restricted to arthropods; $g s$ expression has been reported in mosquito midgut epithelium, ovary, and fat body (Smartt et al. 2001) and in crustacean neural tissues (Linser et al. 1997; Allodi et al. 2006; Sullivan et al. 2007). Our present study, therefore, provides novel information regarding the expression of this enzyme in nonarthropod invertebrates, and our results are in general agreement with those of previous reports; that is, in full-grown E. japonensis, $g s$ is expressed in (1) chloragogen tissues, which correspond to the vertebrate liver in terms of functionality (Jamieson 1981), (2) nephridia, which are the annelid counterparts of the kidney and uterine tube in vertebrates (Jamieson 1981), (3) the brain and ventral nerve cord, (4) the prostomium where large numbers of sensory cells including photoreceptor cells are present (Jamieson 1981; Edwards and Bohlen 1996), (5) the epithelium of the digestive tract, and (6) spermatids and oocytes. 


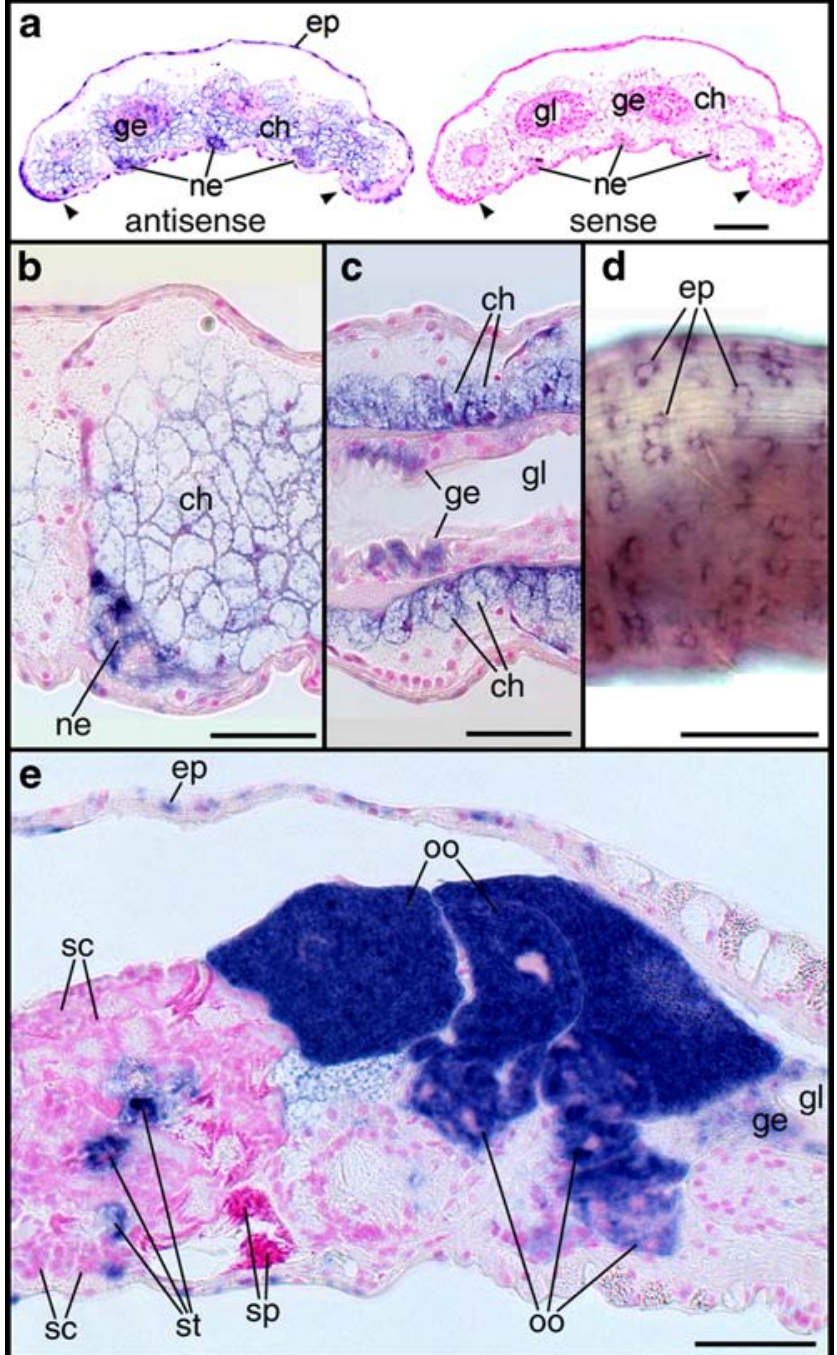

Fig. 3 Glutamine synthetase mRNA expression in nonblastemal tissues. Transcripts were detected by in situ hybridization on paraffin-embedded sections (a-c and $\mathbf{e}$ ) or by whole-mount in situ hybridization (d) using an antisense gs riboprobe, except for the righthand specimen in $\mathbf{a}$. The anterior is to the left, and the ventral side is down in each image. a Sagittal sections of regenerating fragments at about 0.5 days after amputation. The right-hand specimen was hybridized with a sense probe. Arrowheads indicate the amputated sites. b-c Sagittal sections of intact worms. d Whole-mount in situ hybridization analysis of an intact worm showing $g s$ expression in the epidermal cells. e Sagittal section of a sexually mature worm. ch Chloragocyte, ep epidermal cell, ge gut epithelium, $g l$ gut lumen, ne nephridium, oo oocyte, $s c$ spermatocyte, $s t$ spermatid, $s p$ sperm. Scale bars, $50 \mu \mathrm{m}$

Possible functions of glutamine synthetase in E. japonensis

Regeneration The possible involvement of glutamine synthetase in the regeneration of damaged tissue has been reported in only a few cases. These include the observed increase in $g_{s}$ expression after peripheral motor nerve injury in mouse (Toki et al. 1998) and also in Xenopus tail regeneration in which gs expression was found to be upregulated and could be detected in the terminal vesicle of the regenerating spiral cord (Tazaki et al. 2005). Our present results, together with our previously reported findings, strongly suggest the involvement of glutamine synthetase also in annelid regeneration. In the previous study, we have shown that glutamine synthetase is one of the most abundantly expressed upregulated genes during regeneration in E. japonensis (Myohara et al. 2006), and in the present study, our detailed expression analysis by in situ hybridization has revealed strong $g s$ expression in the blastemal regions of regenerating $E$. japonensis. It has been reported previously in Xenopus that embryos abundantly express glutamine synthetase in the developing nervous system during the gastrula and neurula stages (Hatada et al. 1995). In accordance with this finding, we observed in the present analyses that $g_{S}$ is expressed in the presumptive regions of the brain and ventral nerve cord anlagen in the blastema during E. japonensis regeneration. This further suggests the involvement of glutamine synthetase in annelid neural regeneration.

Nerve function Glutamine synthetase has been shown to play an important role in glutamate transmitter degradation in the nervous system (Derouiche and Frotscher 1991) and is used as a specific glial cell marker in the neural retina (Vardimon et al. 1993). In intact E. japonensis, the expression of this enzyme was evident in the brain and ventral nerve cord, suggesting that it has a nervous system function. Its expression in the prostomium may also be attributable to the distribution of numerous sensory cells, probably including photoreceptor cells, in this region (Jamieson 1981; Edwards and Bohlen 1996).

Cell proliferation Glutamine synthetase is the only enzyme that can synthesize glutamine, which provides nitrogen for the synthesis of amino acids, purines, pyrimidines, and other compounds required in many critical cellular events including proliferation (Meister 1980). In the rat intestinal epithelium, high concentrations of glutamine synthetase protein and mRNA have been found in the highly proliferative crypt region (Roig et al. 1995). Hence, the high $g s$ expression levels that we observed in blastemal cells and in the growth zone in actively growing worms could be explained, at least in part, by a high demand for glutamine during the intense cell proliferation that would be ongoing in these areas.

Detoxification Glutamine synthetase is also important for the detoxification of excess glutamate and ammonia by converting them to glutamine, which is nontoxic and can be stored in tissues or circulate throughout the body without causing any harm (Meister 1980). A comparison between the cellular concentrations of glutamine synthetase in various murine organs in a previous report has also revealed 
that the highest concentrations of this enzyme positively correlate with the cells that have detoxifying functions (van Straaten et al. 2006). The $g s$ expression that we observed in the nephridia and chloragocytes in E. japonensis herein could therefore be ascribed to the involvement of these tissues in excretion of nitrogenous waste in oligochaete annelids (Jamieson 1981).

Macromolecule synthesis Glutamine is known to be required for the synthesis of certain macromolecules that are present in mucus, such as the hexosamines that lubricate and protect the gut mucus (Weiss et al. 1999). The mucus secreted by epidermal cells covering the earthworm body is also essential for locomotion, gas exchange, and protection in these animals (Jamieson 1981), and hexosamines have been found to be a component of their cuticles (Muir and Lee 1970). We speculate therefore that the $g s$ transcripts in the E. japonensis epidermal cells have a role in mucus and/or cuticle synthesis in intact and regenerating individuals. In addition, the $g s$ expression found in epithelial cells of the buccal and pharyngeal cavities may be attributed to cuticle synthesis in these tissues (Jamieson 1981).

Gametogenesis Glutamine synthetase expression in the ovary has been reported in Xenopus (Hatada et al. 1995) and in the yellow fever mosquito (Smartt et al. 2001). In oligochaete annelids, the testes and ovaries are small organs located in the ventral part of the genital segments (Edwards and Bohlen 1996). The spermatogonia that are formed in the annelid testes pass into the seminal vesicles, which contain male cells at all stages of development. Oogonia in annelids are formed in the ovaries and divide to form oocytes, which are shed from the ovaries into the ovisacs. In E. japonensis, $g s$ transcripts were detectable in spermatids in the seminal vesicles and in oocytes in the ovisacs but not in the testes or ovaries, suggesting that glutamine synthetase may have a role in the later stage of gametogenesis.

In summary, in the present study, we have characterized an annelid $g s$ gene and shown that it is expressed in a tissuespecific manner in regenerating and intact E. japonensis. To further elucidate the actual functions of this gene, additional studies including RNAi gene knockdown experiments will be needed in the future. Ongoing investigations in our laboratory of other regeneration-associated upregulated genes, several of which are novel (Myohara et al. 2006), should also shed important new light on the network of biological pathways involved in the regenerative processes in E. japonensis.

Acknowledgments We thank M. Hatakeyama and D. S. Yamamoto for their helpful comments and support. This work was supported by a Grant-in-Aid (BioDesign Program) from the Ministry of Agriculture, Forestry, and Fisheries, Japan.
Open Access This article is distributed under the terms of the Creative Commons Attribution Noncommercial License which permits any noncommercial use, distribution, and reproduction in any medium, provided the original author(s) and source are credited.

\section{References}

Abe S, Katagiri T, Saito-Hisaminato A, Usami S, Inoue Y, Tsunoda T, Nakamura Y (2003) Identification of CRYM as a candidate responsible for nonsyndromic deafness, through cDNA microarray analysis of human cochlear and vestibular tissues. Am J Hum Genet 72:73-82

Allodi S, Bressan CM, Carvalho SL, Cavalcante LA (2006) Regionally specific distribution of the binding of anti-glutamine synthetase and anti-S100 antibodies and of Datura stramonium lectin in glial domains of the optic lobe of the giant prawn. Glia 53:612-620

Carlson BM (1998) Development and regeneration, with special emphasis on the amphibian limb. In: Ferretti P, Géraudie J (eds) Cellular and molecular basis of regeneration: from invertebrates to Human. Wiley, Chichester, NY, pp 411-450

Derouiche A, Frotscher M (1991) Astroglial processes around identified glutamatergic synapses contain glutamine synthetase: evidence for transmitter degradation. Brain Res 552:346-350

Edwards CA, Bohlen PJ (1996) Biology and ecology of earthworms, 3rd edn. Chapman \& Hall, London

Hatada S, Kinoshita M, Noda M, Asashima M (1995) Identification of a Xenopus glutamine synthetase gene abundantly expressed in the embryonic nervous system but not in adult brain. FEBS Lett 371:287-292

Hoshino M, Sone M, Fukata M, Kuroda S, Kaibuchi K, Nabeshima Y, Hama C (1999) Identification of the stef gene that encodes a novel guanine nucleotide exchange factor specific for Rac1. J Biol Chem 274:17837-17844

James LA, Lunn PG, Elia M (1998) Glutamine metabolism in the gastrointestinal tract of the rat assessed by the relative activities of glutaminase (EC 3.5.1.2) and glutamine synthetase (EC 6.3.1.2). Br J Nutr 79:365-372

Jamieson BGM (1981) The ultrastructure of the oligochaeta. Academic, London

Kumada Y, Benson DR, Hillemann D, Hosted TJ, Rochefort DA, Thompson CJ, Wohlleben W, Tateno Y (1993) Evolution of the glutamine synthetase gene, one of the oldest existing and functioning genes. Proc Natl Acad Sci USA 90:3009-3013

Linser PJ, Trapido-Rosenthal HG, Orona E (1997) Glutamine synthetase is a glial-specific marker in the olfactory regions of the lobster (Panulirus argus) nervous system. Glia 20:275-283

Meister A (1980) Catalytic mechanism of glutamine synthetase; overview of glutamine metabolism. In: Mora J, Palacios R (eds) Glutamine: metabolism, enzymology and regulation. Academic, London, pp 1-40

Mommsen TP, Busby ER, von Schalburg KR, Evans JC, Osachoff HL, Elliott ME (2003) Glutamine synthetase in tilapia gastrointestinal tract: zonation, cDNA and induction by cortisol. J Comp Physiol B 173:419-427

Muir L, Lee YC (1970) Glycopeptides from earthworm cuticle collagen. J Biol Chem 245:502-509

Murray BW, Busby ER, Mommsen TP, Wright PA (2003) Evolution of glutamine synthetase in vertebrates: multiple glutamine synthetase genes expressed in rainbow trout (Oncorhynchus mykiss). J Exp Biol 206:1511-1521

Myohara M (2004) Differential tissue development during embryogenesis and regeneration in an annelid. Dev Dyn 231:349-358 
Myohara M, Yoshida-Noro C, Kobari F, Tochinai S (1999) Fragmenting oligochaete Enchytraeus japonensis: a new material for regeneration study. Dev Growth Differ 41:549-555

Myohara M, Niva CC, Lee JM (2006) Molecular approach to annelid regeneration: cDNA subtraction cloning reveals various novel genes that are upregulated during the large-scale regeneration of the oligochaete, Enchytraeus japonensis. Dev Dyn 235:2051-2070

Pesole G, Bozzetti MP, Lanave C, Preparata G, Saccone C (1991) Glutamine synthetase gene evolution: a good molecular clock. Proc Natl Acad Sci USA 88:522-526

Reddien PW, Alvarado AS (2004) Fundamentals of planarian regeneration. Ann Rev Cell Dev Biol 20:725-757

Roig JC, Shenoy VB, Chakrabarti R, Lau JY, Neu J (1995) Localization of rat small intestine glutamine synthetase using immunofluorescence and in situ hybridization. JPEN J Parenter Enteral Nutr 19:179-181

Schmelz RM, Collado R, Myohara M (2000) A taxonomic study of Enchytraeus japonensis: morphological and biochemical comparisons with E. bigeminus. Zool Sci 17:505-516

Smartt CT, Kiley LM, Hillyer JF, Dasgupta R, Christensen BM (2001) Aedes aegypti glutamine synthetase: expression and gene structure. Gene 274:35-45

Sullivan JM, Benton JL, Sandeman DC, Beltz BS (2007) Adult neurogenesis: a common strategy across diverse species. J Comp Neurol 500:574-584
Tazaki A, Kitayama A, Terasaka C, Watanabe K, Ueno N, Mochii M (2005) Macroarray-based analysis of tail regeneration in Xenopus laevis larvae. Dev Dyn 233:1394-1404

Thompson JD, Higgins DG, Gibson TJ (1994) CLUSTAL W: improving the sensitivity of progressive multiple sequence alignment through sequence weighting, position-specific gap penalties and weight matrix choice. Nucleic Acids Res 22: $4673-4680$

Thouveny Y, Tassava RA (1998) Regeneration through phylogenesis. In: Ferretti P, Géraudie J (eds) Cellular and molecular basis of regeneration: from invertebrates to humans. Wiley, Chichester, NY, pp 9-44

Toki H, Namikawa K, Su Q, Kiryu-Seo S, Sato K, Kiyama H (1998) Enhancement of extracellular glutamate scavenge system in injured motoneurons. J Neurochem 71:913-919

van Straaten HW, He Y, van Duist MM, Labruyere WT, Vermeulen JL, van Dijk PJ, Ruijter JM, Lamers WH, Hakvoort TB (2006) Cellular concentrations of glutamine synthetase in murine organs. Biochem Cell Biol 84:215-231

Vardimon L, Ben-Dror I, Havazelet N, Fox LE (1993) Molecular control of glutamine synthetase expression in the developing retina tissue. Dev Dyn 196:276-282

Weiss MD, DeMarco V, Strauss DM, Samuelson DA, Lane ME, Neu J (1999) Glutamine synthetase: a key enzyme for intestinal epithelial differentiation? JPEN J Parenter Enteral Nutr 23:140-146 